\title{
Hubungan Praktik Manajemen Sumber Daya Manusia pada Kinerja Perguruan Tinggi di Kalimantan
}

\author{
Andre Suandi Simbolon ${ }^{1}$, Roni Padliansyah ${ }^{2}$, Erick Karunia ${ }^{3}$ \\ ${ }^{1}$ Program Studi Manajemen, Universitas Terbuka, andre.simbolon@ecampus.ut.ac.id \\ 2Jurusan Akuntansi, Universitas Borneo Tarakan, ronipadliansyah@gmail.com \\ ${ }^{3}$ Program Studi Manajemen, Universitas Borneo Tarakan, erickkarunia3@gmail.com
}

\begin{abstract}
Most studies on human resource management practices focus only on their effects on firm performance, especially in the private sector. This study aims to examine the impact of human resource management (HRM) practices on organizational performance, namely universities in Kalimantan. This research was conducted with a cross-sectional SEM-PLS study with simple random sampling. The samples in this study were all employees consisting of both lecturers and education staff at 200 universities in Kalimantan. This survey questionnaire consists of 35 items covering HR practice and university performance. This study has confirmed that human resource management practices such as: recruitment, training, performance appraisal, career planning, job definition, employee participation, and compensation have a positive and significant relationship to college performance. This study also confirms that if the university wants to raise its performance to a higher level, it can emphasize job definition, training and employee participation. The results of this study may not be generalized across Indonesia. However, it can be used as a reference by universities that want to improve their performance to a higher level.
\end{abstract}

Keywords: human resource management practice, university performance

\begin{abstract}
ABSTRAK
Sebagian besar studi tentang praktik manajemen sumber daya manusia hanya berfokus pada pengaruhnya pada kinerja perusahaan terutama di sektor swasta. Penelitian ini bertujuan untuk mengetahui hubungan antara praktik manajemen sumber daya manusia (MSDM) dengan kinerja organisasi yaitu perguruan tinggi di Kalimantan. Penelitian ini dilakukan dengan studi Structural Equation Modeling-Partial Least Square (SEM-PLS) dengan menggunakan data karyawan yang terdiri dari baik dosen maupun tenaga kependidikan di 200 perguruan tinggi di Kalimantan. Kuesioner yang digunakan dalam penelitian ini terdiri dari 35 item mencakup praktik MSDM dan kinerja perguruan tinggi. Penelitian ini telah mengkonfirmasi bahwa praktik manajemen sumber daya manusia seperti : perekrutan, pelatihan, penilaian kinerja, perencanaan karir, definisi pekerjaan, partisipasi karyawan, dan kompensasi memiliki hubungan yang positif dan signifikan terhadap kinerja perguruan tinggi. Untuk itu, apabila pihak universitas ingin meningkatkan kinerjanya ke tingkat yang lebih tinggi, dapat menekankan pada definisi pekerjaan, pelatihan dan partisipasi karyawan. Hasil dari penelitian ini mungkin tidak dapat digeneralisasi di seluruh Indonesia. Tetapi dapat dimanfaatkan sebagai salah satu referensi oleh perguruan tinggi yang ingin meningkatkan kinerjanya ke tingkat yang lebih tinggi.
\end{abstract}

Kata Kunci : praktik manajemen sumber daya manusia, kinerja perguruan tinggi.

Accepted: 01-02-2021, Revision: 28-01-2021, Published: 01-04-2021

\section{PENDAHULUAN}

Sumber daya manusia (SDM) adalah salah satu aset terpenting organisasi yang berkontribusi dalam pertumbuhan dan kesuksesan suatu organisasi. Era digital dengan karakteristik adanya perubahan yang cepat dan berkesinambungan, membuat organisasi perlu memiliki sumber daya manusia yang memiliki kinerja baik, agar tetap produktif dan responsif dalam memenuhi kebutuhan untuk pengembangan organisasi (Nas, 2016). Universitas sebagai lembaga yang melaksanakan Tri dharma pendidikan dalam menunjang aktivitas organisasinya, perlu merekrut, mempertahankan, dan mengembangan SDM. Untuk itu, universitas membutuhkan karyawan yang terlatih dan memiliki motivasi tinggi agar mereka berkomitmen untuk melakukan pekerjaan mereka seperti pengajaran, penelitian dan pegabdian masyarakat untuk pengembangan bangsa dan negara (Valeau \& Paillé, 2019).

Penelitian terdahulu telah menunjukkan penerapan yang efektif dari beberapa manajemen sumber daya manusia (MSDM yang membuktikan bahwa karyawan universitas dapat berkomitmen untuk melakukan pekerjaan dengan baik sehingga dapat meningkatkan kinerja universitas (Bowra, 
Sharif, Saeed, \& Niazi, 2012). Jadi, dengan adanya implementasi praktik MSDM yang tepat pada karyawan universitas akan dapat meningkatkan kinerja universitas sebagaimana Lew (2008) mencatat bahwa karyawan memainkan peran yang penting dalam meningkatkan peringkat di bidang utama pendidikan seperti kualitas penelitian, reputasi akademik fakultas, kualitas program akademik, kontribusi penelitian kepada masyarakat, persiapan pemimpin masa depan dan kualitas lulusan. Menyadari pentingnya promosi kinerja universitas, banyak universitas di dunia yang memulai menyusun strategi praktik MSDM.

Tak terkecuali di Indonesia, pemberian pendidikan yang bermutu bagi masyarakat telah menjadi program prioritas pemerintah sejak dulu, hal ini telah dituangkan dalam Peraturan Pemerintah Nomor 19 Tahun 2005 tentang Standar Nasional Pendidikan sebagaimana yang telah diubah dengan . Bagaimanapun juga pendidikan yang bermutu tidak dapat dicapai tanpa terlebih dahulu meningkatkan kinerja universitasuniversitas di Indonesia. Bahkan pemerintah saat ini bercita-cita untuk mengupayakan universitasuniversitas di Indonesia menjadi pusat penelitian internasional untuk kelas dunia melalui pengembangan universitas terkemuka. Untuk mewujudkan cita-cita ini, penting untuk menyadari bahwa meningkatkan universitas ke kelas dunia dan menaikkan peringkat universitas yaitu dengan cara menarik dan mempertahankan akademisi yang unggul dan berpengalaman serta staf pendukung yang berkinerja baik.

Pada 2014, Pemerintah Indonesia mengkampanyekan revolusi mental, yang pada dasarnya membutuhkan dukungan kualitas institusi pendidikan yang baik. Salah satu sektor yang akan memainkan peran penting adalah pendidikan terutama pendidikan tinggi. Bangsa ini membutuhkan lebih banyak sumber daya manusia yang mampu melakukan berbagai kegiatan baik di sektor publik maupun swasta. Selanjutnya, semakin tinggi pembelajaran di perguruan tinggi diharapkan menghasilkan sumber daya manusia yang berkualitas tinggi pula. Pelatihan dan pengembangan sumber daya manusia yang berkualitas akan tergantung pada kinerja dari universitas (Malik, Nawab, Naeem, \& Danish, 2010). Sehingga diperlukan praktik MSDM seperti seleksi, kompensasi, berbagi informasi, pengambilan keputusan partisipatif, definisi pekerjaan, pelatihan, perencanaan karir dan manajemen kinerja (Smeenk, Eisinga, Teelken, \& Doorewaard, 2006).

Studi tentang dampak praktik sumber daya manusia terhadap kinerja dengan khususnya rujukan di Indonesia hanya berfokus pada sektor swasta (Hidayat, 2018; Isdianto \& Kurniawan,
2017). Padahal terdapat studi sebelumnya di tempat lainnya yang berfokus pada dampak praktik MSDM pada kinerja organisasi dengan akademisi sebagai pusat fokus (Lee et al., 2012; Malik et al., 2010). Penelitian empiris yang telah dilakukan untuk menguji efek dari Praktik MSDM pada kinerja perguruan tinggi di Indonesia sangat terbatas. Oleh karena itu, penelitian ini diharapkan dapat memberikan bukti empiris dampak praktik MSDM terhadap kinerja perguruan tinggi di Indonesia dengan fokus khusus pada perguruan tinggi di Kalimantan.

Pada bagian selanjutnya akan mengulas tinjauan literatur dan pengembangan hipotesis, lalu diikuti oleh penjelasan sampel dan teknik pengumpulan data serta teknik analisis data dan pengujian hipotesis.

\section{KAJIAN LITERATUR}

Penelitian sebelumnya telah menemukan bahwa praktik MSDM berpengaruh pada kinerja karyawan dan keunggulan kompetitif suatu organisasi (Khan, Md Yusoff, Hussain, \& Binti Ismail, 2019). Pfeffer (1994) mengidentifikasi 16 praktik yang dapat meningkatkan keunggulan kompetitif perusahaan seperti keamanan kerja, selektivitas dalam perekrutan, berbagi informasi, partisipasi dan pemberdayaan, pelatihan dan pengembangan keterampilan, insentif, upah tinggi, dan promosi. Sementara itu, Guest (2002) berpendapat bahwa dampak dari Praktik MSDM pada kinerja organisasi tergantung pada respon pekerja terhadap praktik MSDM. Jika karyawan memiliki persepsi negatif, kinerja organisasi akan rendah dan sebaliknya apabila karyawan memiliki persepsi positif, kinerja organisasi akan meningkat. Selanjutnya, Ekaterini (2010) menegaskan kembali Temuan Wright, Gardner, and Moynihan (2003) bahwa sifat sumber daya manusia yang di kendalikan dengan baik dapat berdampak pada karyawan dan kinerja perusahaan.

Efektivitas karyawan sebagian besar tergantung pada dampak praktik MSDM pada perilaku karyawan. Sementara itu, Huselid (1995) mengidentifikasi rekrutmen dan seleksi, pelatihan dan pengembangan, partisipasi dan penghargaan sebagai praktik MSDM. Pelatihan dan pengembangan, kerja tim, penilaian kinerja, kompensasi / insentif, perencanaan sumber daya manusia dan bantuan keamanan pekerjaan dapat meningkatkan kinerja termasuk peningkatan produktivitas karyawan, kualitas produk dan fleksibilitas perusahaan. Di sisi lain, Quresh, Akbar, Khan, Sheikh, and Hijazi (2010) mengkategorikan praktik MSDM ke dalam sistem seleksi, pelatihan, definisi pekerjaan, sistem penilaian kinerja, kompensasi, sistem perencanaan karir dan partisipasi karyawan. Oleh karena itu, 
untuk tujuan penelitian ini, praktik-praktik MSDM yang dipertimbangkan adalah sebagai berikut: rekrutmen, pelatihan, penilaian kinerja, perencanaan karir, definisi pekerjaan, partisipasi karyawan dan kompensasi.

\section{Hubungan Praktik MSDM dan Kinerja Universitas}

Organisasi menerapkan praktik dan sistem MSDM untuk memanfaatkan potensi kekuatan karyawan untuk mempertahankan keunggulan kompetitif. Juga telah ditemukan bahwa ada hubungan positif dan signifikan antara praktik MSDM dan kinerja organisasi (Lee et al., 2012) Sementara itu, Abdullah, Ahsan, and Alam (2009) menyoroti pelatihan dan pengembangan, pekerjaan tim, penilaian kinerja dan perencanaan sumber daya manusia berpengaruh langsung terhadap performa bisnis. (Khan et al., 2019) menemukan bahwa integrasi pendekatan terhadap praktik MSDM akan meningkatkan kepuasan dan komitmen karyawan yang akibatnya mengarah pada meningkatnya kinerja individu dan tim secara luar biasa.

Studi sebelumnya tentang hubungan antara praktik MSDM dan kinerja perusahaan menggunakan balanced score card (BSC) atau key performance indicators (KPI) (Abdullah et al., 2009). Namun, terdapat sangat sedikit literatur yang mendukung penerapan BSC atau KPI di sektor pendidikan. Saat ini tidak ada consensus atau kesepakatan tentang BSC atau KPI untuk menilai kinerja universitas. Meskipun demikian, elemen BSC cenderung sejalan dengan KPI terkait untuk pengajaran, pembelajaran dan pertumbuhan, penelitian, keuangan, layanan pelanggan, siswa pengalaman, manajemen dan tata kelola antara lain. Pembahasan selanjutnya akan berfokus pada pengembangan hipotesis.

\section{Hubungan Rekrutmen dan Seleksi, dan Kinerja Organisasi}

Rekrutmen didefinisikan sebagai proses dimana organisasi menemukan dan menarik individu untuk mengisi lowongan pekerjaan Tarique, Briscoe, and Schuler (2015). Juga dapat didefinisikan sebagai praktik atau kegiatan yang dilakukan oleh organisasi dengan tujuan utama mengidentifikasi dan menarik karyawan yang potensial. Sedangkan, seleksi adalah proses mengurangi jumlah dan memilih diantara individu yang memiliki kualifikasi yang relevan. Namun ketika organisasi gagal menemukan orang yang cocok untuk dinilai dan dipilih, maka berakibat pada gagalnya organisasi dalam mencapai tujuan dan akan menghadapi berbagai masalah personil seperti: pergantian personilm yang tinggi, produktivitas rendah, tingkat absensi yang tinggi dan stres karyawan (Wickramasinghe \& Gamage, 2011). Karena itu, untuk memaksimalkan keunggulan daya saing, suatu perusahaan harus memilih metode rekrutmen yang menghasilkan kumpulan terbaik kandidat secara efisien dan efektif.

Perekrutan adalah salah satu fungsi utama MSDM dan membantu manajer menarik dan memilih kandidat terbaik yang pada gilirannya mengarah pada peningkatan kinerja organisasi (Rehman, 2012). Metode rekrutmen formal termasuk koran yang diklasifikasikan sebagai iklan, jaringan buletin, poster dan bank data sumber daya manusia, sementara metode informal mencakup hubungan pribadi dan perkenalan melalui guru dan staf lainnya. Efektivitas rekrutmen yang berbeda terhadap sumber untuk karyawan baru telah menjadi topik spekulasi dalam sepanjang penelitian MSDM sebelumnya dan keefektifan ini terutama dinilai dengan memeriksa tingkat kelangsungan hidup pekerjaan dan kinerja pekerjaan (Rehman, 2012). menemukan bahwa efektivitas praktik rekrutmen berdampak pada efektivitas organisasi. Demikian pula, banyak peneliti setuju bahwa rekrutmen dan seleksi yang efektif akan mengarah pada keunggulan kompetitif dan kinerja organisasi yang tinggi (Pfeffer, 1994). Berdasarkan penjelasan diatas, maka disusunlah hipotesis berikut:

H1. Diduga perekrutan dan seleksi memiliki hubungan yang positif dan signifikan dengan kinerja organisasi.

\section{Hubungan Pelatihan dan Kinerja Organisasi}

Pelatihan mengacu pada metode yang digunakan untuk memberikan karyawan baru atau karyawan lama keterampilan, pengetahuan dan kemampuan lain yang mereka butuhkan untuk melakukan pekerjaan mereka (Daley, 2012). Pelatihan dimaksudkan untuk memodifikasi keterampilan individu atau sikap. Pelatihan juga berkontribusi pada pengembangan disposisi positif terhadap pertumbuhan dan perubahan yang diberlakukan oleh individu sebagai serta kelompok dan tim. Mengingat semakin kompleksnya tugas dan keterampilan yang dibutuhkan dalam masyarakat modern, mengembangkan strategi pelatihan yang efektif memiliki dampak praktis yang luar biasa, seperti pelatihan yang dapat meningkatkan kinerja baik tugas yang membutuhkan kemampuan tinggi maupun tidak (Lee et al., 2012). Pelatihan dalam meningkatkan kemampuan karyawan berperan penting meningkatkan kinerja organisasi secara keseluruhan. Penelitian sebelumnya mengungkapkan bahwa ada hubungan yang positif antara pelatihan dan kinerja organisasi (Khan et 
al., 2019; Quresh et al., 2010). Maka berdasarkan uraian diatas hipotesis berikut ini dibentuk:

H2. Diduga pelatihan memiliki hubungan yang positif dan signifikan dengan kinerja organisasi.

\section{Hubungan Penilaian Kinerja dan Kinerja Organisasi}

Penilaian kinerja dapat didefinisikan sebagai proses penentuan dan mengkomunikasikan kepada karyawan seberapa baik kinerjanya dalam menyelesaikkan pekerjaan dan idealnya bertujuan untuk menetapkan rencana perbaikan kedepan (Rogers, Creed, \& Glendon, 2008). Penilaian terdiri dari evaluasi obyektif dari gabungan kinerja karyawan dengan garis besar langkah-langkah yang harus diambil untuk perbaikan dan ditandatangani oleh kedua belah pihak baik karyawan maupun manajer. Literatur sebelumnya menunjukkan bahwa ada hubungan yang signifikan antara penilaian kinerja dan kinerja organisasi (Quresh et al., 2010). Praktik MSDM komplementer, yaitu pelatihan formal dan gaji insentif dapat meningkatkan penilaian kinerja karyawan yang mengarah ke pengaruh yang lebih besar terhadap produktifitas. Mengelola kinerja karyawan merupakan bagian integral dari suatu organisasi dan mencerminkan bagaimana mereka mengelola sumber daya manusia mereka. Selain itu, praktik penilaian yang tidak efektif dapat menyebabkan banyak masalah yang tidak diinginkan termasuk semangat kerja rendah, produktivitas karyawan menurun dan antusiasme rendah untuk mendukung organisasi, karenanya dapat menurunkan kinerja organisasi (Osman, Ho, \& Galang, 2011). Bahkan, penilaian kinerja yang efektif harus mencakup keseluruhan kerangka kerja atau konteks yang memungkinkan seluruh proses beroperasi pada tingkat kinerja yang optimal. Oleh karena itu, hipotesis berikut dibentuk berdasarkan penjelasan diatas:

H3. Diduga penilaian kinerja memiliki hubungan yang positif dan signifikan dengan kinerja organisasi.

\section{Hubungan Perencanaan Karir dan Kinerja Organisasi}

Perencanaan karir adalah proses yang disengaja di mana seseorang menjadi sadar akan keterampilan, minat, pengetahuan, motivasi, dan karakteristik pribadinya; memperoleh informasi tentang peluang dan pilihan; mengidentifikasi tujuan yang berhubungan dengan karier; dan menetapkan rencana aksi untuk mencapai tujuan tertentu (Abdulkadir, Isiaka, \& Adedoyin, 2012). Hal itu selaras dengan strategi memenuhi kebutuhan sumber daya manusia masa depan dan bersifat integral untuk proses pengembangan karir (Rogers et al., 2008). Banyak peneliti setuju bahwa perencanaan karir mempengaruhi kinerja keduanya baik karyawan maupun organisasi (Osman et al., 2011). Merencanakan karir dan mengeksplorasi potensi pilihan karir adalah tindakan yang dirancang untuk menerapkan tujuan seseorang untuk meningkatkan pengembangan yang menjurus (Rogers et al., 2008). Ini membantu menyeimbangkan preferensi dan kemampuan karyawan dan permintaan organisasi. Dengan kata lain, perencanaan karir dan pengembangan sebagai proses, menyelaraskan minat dan keterampilan karyawan dengan kebutuhan organisasi (Nwuche \& Awa, 2011) yang pada gilirannya mengarah pada peningkatan kinerja organisasi. Diskusi karena itu, menyarankan yang berikut ini hipotesa: H4. Diduga perencanaan karir memiliki hubungan yang positif signifikan dengan organisasi kinerja.

\section{Hubungan Definisi Pekerjaan dan Kinerja Organisasi}

Deskripsi pekerjaan menguraikan tugas dan tanggung jawab penting yang diharapkan dari karyawan dan dasar tujuan pekerjaan yang diharapkan dilakukan oleh karyawan. Dengan demikian, uraian tugas memiliki arti adalah dokumen yang layak menentukan kesuksesan organisasi atau, sebaliknya jika tidak ada, memungkinkan iklim kebingungan, praktik kerja yang buruk, evaluasi kinerja yang tidak jelas dan subyektif, dan ketidakharmonisan organisasi (Manning, Borton, \& Rumovitz, 2012). Mayoritas kesalahan perekrutan yang dibuat bisa dicegah jika orang-orang bertanggung jawab atas perekrutan dan melakukan pekerjaan yang efektif untuk menentukan dengan tepat apa yang mereka cari sebelum mereka mulai mencari kandidat. Deskripsi dan spesifikasi pekerjaan yang tepat yang berasal dari analisis pekerjaan secara jelas menguraikan tugas, tanggung jawab, kondisi kerja dan yang diharapkan keterampilan seorang individu dalam melakukan suatu pekerjaan (Manning et al., 2012). Abeysekera (2007)berpendapat bahwa melakukan analisis pekerjaan dan kemudian memberikan karyawan deskripsi pekerjaan dapat mencegah situasi di mana karyawan tidak tahu apa yang diharapkan dari mereka. Terdapat hubungan langsung antara kekuatan dan efektivitas suatu organisasi dan kualitas deskripsi pekerjaan (Manning et al., 2012). Dengan informasi yang dikumpulkan selama langkah analisis pekerjaan, seorang manajer akan dapat meningkatkan deskripsi pekerjaan sesuai kebutuhan. Deskripsi pekerjaan yang tepat akan mengarah kepada efektivitas perusahaan. Demikianlah berikut ini hipotesis yang diajukan:

H5. Diduga deskripsi pekerjaan memiliki hubungan yang positif signifikan dengan kinerja organisasi. 


\section{Hubungan Partisipasi Karyawan dan Kinerja Organisasi}

Partisipasi adalah mekanisme dialog kerja di antara para pekerja, yang mana dapat memberi mereka kesempatan untuk bertukar informasi dan ide (Zerella, Von Treuer, \& Albrecht, 2017). Konsep ini adalah sebuah pengaturan yang memastikan bahwa karyawan diberi kesempatan untuk mempengaruhi keputusan manajemen dan untuk berkontribusi pada peningkatan kinerja organisasi (Abdulkadir et al., 2012). Partisipasi adalah tentang bagaimana karyawan memainkan peran yang lebih besar dalam proses pengambilan keputusan dan akan mengarah pada efektivitas kinerja perusahaan. Terdapat bukti yang menunjukkan bahwa partisipasi karyawan dapat meningkatkan kinerja perusahaan (Khan et al., 2019; Osman et al., 2011; Quresh et al., 2010). Sebagai contoh, Daley (2012) mempertimbangkan keunggulan manufaktur, daya saing dan kemampuan perusahaan untuk terus berinovasi agar bergantung antara lain pada partisipasi dan keterlibatan karyawan di berbagai tingkatan. Selanjutnya, TQM organisasi, misalnya, menggunakan pendekatan partisipatif dalam pengambilan keputusan karena melakukan hal itu dapat menawarkan sejumlah manfaat. Pada waktu bersamaan, sarana partisipasi tidak langsung, seperti organisasi pekerja, dapat berperan dan bermanfaat untuk organisasi, sehingga berdasarkan uraian di atas Hipotesis berikut diusulkan

H6. Diduga partisipasi memiliki hubungan yang positif signifikan dengan kinerja organisasi.

\section{Hubungan Kompensasi dan Kinerja Organisasi} Kompensasi adalah sistem imbalan yang diberikan perusahaan kepada individu secara bergantian terhadap kesediaan mereka untuk melakukan berbagai pekerjaan dan tugas dalam organisasi (Küster \& Canales, 2011). Penghargaan yang sesuai dan adil perlu diberikan kepada karyawan sehingga mereka merasa dihargai dan hadiahnya sesuai dengan keterampilan, kemampuan dan kontribusi kepada perusahaan. Telah ditemukan bahwa ada hubungan yang signifikan antara kompensasi dan kinerja karyawan dan organisasi (Khan et al., 2019; Quresh et al., 2010). Sebagai contoh, Valeau and Paillé (2019) menemukan bahwa kemampuan perusahaan untuk menarik, memotivasi dan mempertahankan karyawan dengan menawarkan gaji kompetitif dan imbalan yang sesuai berdampak pada pertumbuhan dan kinerja perusahaan. Di sisi lain Küster and Canales (2011) menemukan bahwa sistem kompensasi yang digunakan untuk tenaga penjualan memiliki efek signifikan pada kinerja individu tenaga penjual dan efektivitas organisasi penjualan. Karena itu, selamanya di lingkungan bisnis yang kompetitif, banyak perusahaan saat ini berusaha mengidentifikasi strategi kompensasi inovatif yang terkait langsung dengan peningkatan kinerja organisasi. Maka, hipotesis yang diusulkan seperti di bawah ini:

H7. Diduga kompensasi memiliki hubungan yang positif signifikan dengan kinerja organisasi.

\section{METODE PENELITIAN}

Populasi dalam penelitian ini adalah seluruh perguruan tinggi di Indonesia. Dalam hal keterbatasan waktu dan dana penelitian maka perguruan tinggi yang dipilih sebagai sample adalah seluruh perguruan tinggi di Kalimantan. Probability sampling dengan teknik simple random sampling akan digunakan dalam penelitian ini. Probability sampling adalah prosedur terkontrol yang menjamin bahwa setiap elemen populasi diberi kesempatan yang sama dan dapat memberikan perkiraan presisi. Kuesioner didistribusikan secara merata kepada tenaga pengajar (dosen) dan staf pendukung di semua fakultas dan kantor administrasi perguruan tinggi di Kalimantan. Instrumen kuesioner diadaptasi dari Shiah-Hou and Cheng (2012), dan Quresh et al. (2010) yang dibagi menjadi tiga bagian: Praktik Manajemen Sumber Daya Manusia (MSDM), Kinerja dan Demografi Perguruan Tinggi. Bagian pertama terdiri 35 item mengukur sejauh mana praktik MSDM termasuk rekrutmen dan seleksi, pelatihan, penilaian kinerja, perencanaan karir, definisi pekerjaan, partisipasi karyawan, kompensasi yang diterapkan dalam perguruan tinggi yang dijadikan sample. Para responden akan diminta untuk menilai 35 elemen berdasarkan lima poin Skala likert. Selanjutnya, pertanyaan meliputi pertanyaan demografis seperti usia, jenis kelamin, kategori staf, lokasi, jurusan/sekolah/fakultas, pengalaman kerja dan kualifikasi akademik.

\section{Teknik Analisis Data}

Dalam penelitian ini structural equation modeling (SEM) - partial least squares (PLS) digunakan untuk mengkonfirmasi dampak praktik manajemen sumber daya manusia pada kinerja perguruan tinggi di Kalimantan. Partial least squares (PLS) structural equation modeling (SEM) digunakan untuk menganalisis data kuisioner yang akan disebarkan kepada responden dalam penelitian ini. Partial least squares saat ini semakin banyak digunakan sebagai teknik analitis, khususnya dalam penelitian tentang organisasi dan MSDM (Kurniasih, 2018; Muiz \& Muchsinati, 2017) persamaan struktural PLS telah menghasilkan bukti yang mendukungnya keunggulan dibandingkan pemodelan berbasis kovarians maupun regresi, sehingga diharapkan 
penelitian ini dapat memberikan hasil yang lebih baik dari penelitian sebelumnya yang terkait MSDM. PLS mampu menghasilkan koefisien yang lebih akurat ketika ada korelasi antara independent variabel. PLS SEM dapat memberikan informasi terkait pengukuran dan komponen dari model struktural.

Analisis data yang digunakan adalah analisis deskriptif berfungsi untuk mendeskripsikan atau memberi gambaran terhadap sampel yaitu seluruh staf akademik dan tenaga pengajar di seluruh universitas di Kalimantan Utara dan Kalimantan Timur serta untuk mengetahui karakteristik serta tanggapan responden terhadap item-item pertanyaan pada kuesioner. Teknik analisis yang digunakan adalah Partial Least Square (PLS) yaitu untuk tujuan memprediksi terutama pada kondisi dimana indikator bersifat formatif. Di dalam PLS model structural hubungan antar variabel laten disebut dengan inner model, sedangkan model pengukuran (bersifat refleksif atau formatif) disebut outer model.

\section{PEMBAHASAN \\ Deskriptif Statistik}

Dari kuesioner yang dibagikan kepada respinden, terkumpul 204 kuesioner. Tabel 1 menunjukkan profil responden. Dari 204 responden, 54 orang berusia di bawah 30 tahun, 102 orang berada dalam rentang 30-40 tahun, 36 orang berada dalam rentang 41-50 tahun, dan 12 orang berusia di atas 50 tahun. Mayoritas responden berusia di bawah 40 tahun. Dari 204 peserta, 62,25 adalah laki-laki dan 37,75 persen adalah perempuan. Dosen dan staf pendukung masing-masing mewakili 87,75 dan 12,25 persen dari total responden.

Table 1. Profil Responden

\begin{tabular}{llll}
\hline Biodata Responden & Range & Frekuensi & $\%$ \\
\hline Umur & $<30$ Tahun & 54 & 26.47 \\
& 30 - 40 Tahun & 102 & 50.00 \\
& $41-50$ Tahun & 36 & 17.65 \\
Kategori Pegawai & $>50$ Tahun & 12 & 5.88 \\
& Dosen & 179 & 87.75 \\
Jenis Kelamin & Staff Pendukung Akademik & 25 & 12.25 \\
& Pria & 127 & 62.25 \\
Total Responden & Wanita & 77 & 37.75
\end{tabular}

Sumber: Data diolah, 2020

Hasil statistik deskriptif data variabel laten atau konstruk yang mempengaruhi Kinerja Universitas yang berguna untuk mengidentifikasi outlier, mean, median dan standar deviasi dirangkum sebai berikut. Dari hasil analisis nilai Perekrutan dan Seleksi relatif tinggi (nilai mean antara 3.63 - 4), hal ini menandakan responden menilai penting perekrutan dan seleksi bagi kinerja universitas. Selain itu, nilai Pelatihan juga cukup tinggi dengan nilai mean antara 3.57 - 3.64 yang dapat diartikan bahwa menurut pendapat responden dosen dan staf perguruan tinggi di Kalimantan pelatihan dapat membantu peningkatan kompetensi yang akan dapat mendukung kinerja universitas. Selanjutnya, Penilaiaan Kinerja juga dianggap mempengaruhi sikap dan prilaku terlihat dari nilanya yang cukup tinggi dengan mean sebesar $3.66-3.80$. Selain itu, Perencanaan Karir bagi dosen dan staf juga menunjukkan mean yang ralatif tinggi ditunjukkan oleh cukup besarnya nilai mean yaitu antara 3.63 3.98. Terakhir, yakni responden meunjukkan kesepahaman dengan cara pengukuran Kinerja Universitas mengunakan item yang di gunakan pada penelitian terlihat dari nilai mean yang cukup tinggi pula yaitu antara $3.32-4.26$.

\section{Pengujian model}

SmartPLS 3.0 digunakan dalam analisis pemodelan persamaan struktural (SEM) untuk memverifikasi model penelitian teoritis dan hipotesis. SEM-Partiat Least Square (PLS) merupakan alat yang menggunakan pendekatan berbasis komponen untuk estimasi, dimana terdapat sedikit kelonggaran dalam hal memberikan pembatasan ukuran sampel dan distribusi residu, dan sangat berguna di suatu topik penelitian dimana terdapat teori yang lemah serta pemahaman yang terbatas tentang hubungan antar variabel. Model PLS dapat dianalisis dan diinterpretasikan dalam dua tahap: (1) model pengukuran (outer model) yang menampilkan hubungan antara konstruk dan indikator dan menilai reliabilitas dan validitas model pengukuran; dan (2) model struktural (inner model) yang merepresentasikan konstruk dan menampilkan hubungan (path) antara konstruk (Hair Jr, Hult, Ringle, \& Sarstedt, 2016) Tahap 1: analisis model pengukuran 
Tabel 2 Hasil Pengujian hipotesis

\begin{tabular}{lrrr}
\hline & Path Coefficients & T Statistics & \multicolumn{2}{c}{ P Values } \\
\hline Perekrutan dan seleksi -> Kinerja Universitas & 0.243 & 3.233 & 0.026 \\
Pelatihan -> Kinerja Universitas & 0.010 & 2.098 & 0.022 \\
Penilaian kinerja -> Kinerja Universitas & 0.306 & 3.533 & 0.012 \\
Perencanaan karir -> Kinerja Universitas & 0.205 & 2.973 & 0.031 \\
Deskripsi pekerjaan -> Kinerja Universitas & 0.264 & 2.657 & 0.048 \\
Partisipasi -> Kinerja Universitas & 0.566 & 4.996 & 0.000 \\
Kompensasi -> Kinerja Universitas & 0.313 & 4.105 & 0.016 \\
\hline
\end{tabular}

Sumber: data diolah dengan SmartPLS v3.2

Untuk menilai model pengukuran, maka dibuatkan gambar hubungan antar laten variabel yang diamati, kemudian di hitung menggunakan algoritma PLS dengan path model (Vinzi, Trinchera, \& Amato, 2010). Studi ini menilai model pengukuran dengan memeriksa: individual item reliability; matrix of loadings and crossloadings; convergent validity; internal consistency; dan discriminant validity. Konsistensi internal mempertimbangkan dua elemen untuk evaluasi yaitu: cronbach's alpha dan composite reliability. Composite reliability mengasumsikan bahwa indikator memiliki loadings yang berbeda dan memprioritaskan indikator yang memiliki reliabilitas tinggi terhadap variabel laten, tidak seperti Cronbach's alpha yang mengasumsikan bahwa semua indikator secara sama dapat diandalkan untuk mengukur variabel laten (Chin, 2010). Cronbach's alpha dan composite reliability yang baik harus lebih besar dari 0.70. Hasil penelitian tentang Kinerja Universitas ini menunjukkan nilai Composite reliability yang dapat diterima yaitu sebesar 0.884 hingga 0.938 dan nilai Cronbach's alpha sebesar 0.836 hingga 0.921. Hal tersebut menunjukkan semua konstruk menunjukkan reabilitas atau keandalan dan konsistensi yang tinggi.

Untuk menetapkan validitas konvergen, perlu untuk mengevaluasi indikator outer loadings, serta rata-rata varian ekstraksi (AVE). Outer loadings yang tinggi menunjukkan indikator terkait memiliki banyak kesamaan. Nilai outer loading yang

baik adalah lebih dari 0.70 . Sedangkan, nilai AVE 0.50 atau lebih tinggi menunjukkan tingkat validitas konvergen yang cukup, artinya bahwa variabel laten menjelaskan lebih dari setengah varian indikatornya (Hair Jr et al., 2016). Beberapa indikator memiliki outer loadings dibawah 0.70 yang mana item tersebut dapat di keluarkan. Lebih lanjut, nilai AVE, yang berkisar diantara 0.590 0.699 berarti semua konstruksi menunjukkan validitas konvergen.

Tahap 2: analisis model struktural
Model struktural menganalisis hubungan antara variabel laten. Dalam analisis model struktural dalam penelitian ini, signifikansi jalur ditentukan dengan mengevaluasi $t$-statistik menggunakan teknik bootstrap dengan 204 sampel. Pendekatan bootstrap adalah pendekatan non-parametrik untuk memperkirakan ketepatan perkiraan PLS (Chin, 2010). Selain itu, untuk menilai kekuatan prediksi model struktural, digunakan nilai $\mathrm{R}^{2}$ dari konstruk endogen. Hal ini dapat mewakili nilai varians dalam konstruk yang dapat dijelaskan oleh model (Chin, 2010).

Tabel 2 berisi hasil pengujian hipotesis menjelaskan tentang jalur hubungan antara variabel perekrutan dan seleksi terhadap kinerja universitas (H1), koefisien beta bertanda positif sebesar 0.243 dan signifikan secara statistik dengan nilai p-value 0.026 (t-statistik = $3.233>1.96)$. Kedua, hubungan antara variabel pelatihan dan kinerja universitas (H2) menunjukkan nilai

koefisien beta sebesar 0.010 dan nilai t-statistik 2.098 dengan p-value 0.022. Ketiga, koefisien jalur dengan beta yang positif dan signifikan (signifikan pada $\mathrm{p}$-value $=0.012$ ) juga ditemukan pada hubungan antara penilaiaan kinerja dan kinerja universitas (H3) dengan koefisien beta $=0.306$; dan t-statistik $=3.553$. Keempat, perencanaan karir dan kinerja universitas (H4) memiliki hubungan positif dan signifikan dengan koefisien beta positif 0.205 , serta signifikan pada nilai p-value 0.031 ; $\mathrm{t}$ statistik 2.973. Kelima, jalur hubungan antara variabel deskripsi pekerjaan terhadap kinerja universitas (H5) ditemukan signifikan pada pvalue 0.048 , serta koefisien beta menunjukkan hubungan positif (beta $=0.264$, t-statistik $=2.657$ ). Keenam, terdapat hubungan positif dan signifikan antara partisipasi dan kinerja universitas (H6) dengan nilai t-statistik 4.996 dengan p-value 0.000 . Terakhir, terdapat variable kompensasi yang menunjukan hubungan positif dan signifikan dengan kinerja universitas (H7) yang terlihat dari 
nilai t-satistik dan p-value secara berturut-turut yaitu 4.105 dan 0.016

Model konseptual dalam penelitian menghasilkan nilai $\mathrm{R}^{2}$ sebesar 0.589 yang berarti variabel endogen yang dijelaskan oleh semua variabel eksogen menunjukkan akurasi prediksi model sebesar $58.9 \%$ yang dapat dikatakan cukup memuaskan. Hal ini, dapat terjadi karena, karena semua $\mathrm{R}^{2}$ ini lebih besar dari tingkat yang direkomendasikan, maka model ini dapat dikatakan tepat untuk memeriksa tingkat signifikansi jalur yang terkait dengan variabel.

\section{SIMPULAN}

Berdasarkan hasil pengujian hipotesis dan pembahasan, maka dapat dirumuskan beberapa kesimpulan sebagai berikut : Perekrutan dan seleksi dosen maupun staf di universitas mempunyai hubungan positif dan signifikan terhadap kinerja universitas, hal ini membuktikan bahwa pola rekrutmen yang baik, seperti siapa orang yang terlibat dalam proses seleksi, isi substansi test yang ilmiah serta dan ketat, serta pemilihan kandidat berdasarkan kemapuan dan pengetahuan dapat meningkatkan kinerja universitas. Pelatihan terhadap dosen maupun staf di universitas mempunyai hubungan positif dan signifikan terhadap kinerja universitas, hasil ini berarti dapat menunjukkan pola-pola pelatihan seperti pelatihan formal di universitas bagi dosen dan staf dapat meningkatkan kinerja universitas. Penilaiaan kinerja bagi dosen dan staf di universitas mempunyai hubungan positif dan signifikan terhadap terhadap kinerja universitas, gambaran hasil tersebut membuktikan bahwa system penilaiaan yang objektif dalam universitas terhadap dosen dan stafnya dalam mengevaluasi kinerja dapat secara langsung meningkatkan kinerja universitas, dan sebaliknya apabila penilaiaan kinerja tidak objektif dan bias maka dapat menurunkan kinerja universitas. Perencanaan karir bagi dosen dan staf di universitas mempunyai hubungan positif dan signifikan terhadap kinerja universitas, hal ini berarti perencanaan karir yang baik oleh dosen dan staf serta promosi kenaikan jabatan berdasarkan prestasi dapat secara langsung dapat meningkatkan kinerja universitas, dan begitu pula sebaliknya. Deskripsi pekerjaan bagi dosen dan staf di universitas mempunyai hubungan positif dan signifikan terhadap kinerja universitas, hasil ini menunjukkan bahwa pengetahuan dan kesadaran dosen dan staf atas definisi pekerjaannya dapat secara langsung mempengaruhi kinerja universitas. Sebaliknya ketidak tahuan dan ketidak pedulian dosen dan staf atas tanggungjawab dan deskripsi pekerjaannya akan menurunkan kinerja universitas. Partisipasi dosen dan staf di universitas mempunyai hubungan positif dan signifikan terhadap kinerja universitas, hasil ini menunjukkan bahwa akses terhadap keterbukaan informasi dan partisipasi aktif dalam memberikan masukkan terkait kebijakan akan berpengaruh langsung terhadap peningkatan kinerja universitas. Kompensasi kepada dosen dan staf mempunyai hubungan positif dan signifikan terhadap kinerja universitas, hal ini berarti bahwa kepuasan atas kompensasi yang diberikan berdasarkan kinerja dan kompetensi dapat secara langsung dapat menunjang peningkatan kinerja universitas.

\section{REFERENSI}

Abdulkadir, D. S., Isiaka, S. B., \& Adedoyin, S. I. (2012). Effects of strategic performance appraisal, career planning and employee participation on organizational commitment: An empirical study. International Business Research, 5(4), 124.

Abdullah, Z., Ahsan, N., \& Alam, S. S. (2009). The effect of human resource management practices on business performance among private companies in Malaysia. International journal of business and management, 4(6), 65-72.

Abeysekera, R. (2007). The impact of human resource management practices on marketing executive turnover of leasing companies in Sri Lanka. Contemporary Management Research, 3(3).

Bowra, Z. A., Sharif, B., Saeed, A., \& Niazi, M. K. (2012). Impact of human resource practices on employee perceived performance in banking sector of Pakistan. African Journal of Business Management, 6(1), 323-332.

Chin, W. W. (2010). How to write up and report PLS analyses. In Handbook of partial least squares (pp. 655-690): Springer.

Daley, D. M. (2012). Strategic human resources management. Public personnel management, 120-125.

Ekaterini, G. (2010). The impact of leadership styles on four variables of executives workforce. International journal of business and management, 5(6), 3.

Guest, D. (2002). Human resource management, corporate performance and employee wellbeing: Building the worker into HRM. The journal of industrial relations, 44(3), 335-358.

Hair Jr, J. F., Hult, G. T. M., Ringle, C., \& Sarstedt, M. (2016). A primer on partial 
least squares structural equation modeling (PLS-SEM): Sage publications.

Hidayat, S. (2018). Pengaruh Praktik Manajemen Sumber Daya Manusia terhadap Kinerja Karyawan di PT. Indo-rama Synthetics Tbk. Divisi Spun Yarns. Eqien: Jurnal Ekonomi dan Bisnis, 5(1), 57-67.

Huselid, M. A. (1995). The impact of human resource management practices on turnover, productivity, and corporate financial performance. Academy of management journal, 38(3), 635-672.

Indonesia, P. R. (2006). Peraturan pemerintah Republik Indonesia Nomor 19 tahun 2005 tentang standar nasional pendidikan.

Indonesia, P. R. (2013). Peraturan Pemerintah No. 32 tahun 2013 tentang Perubahan Atas Peraturan Pemerintah No. 19 tahun 2005 tentang Standar Nasional Pendidikan. Republik Indonesia.

Isdianto, O., \& Kurniawan, I. S. (2017). Pengaruh Praktik Msdm Strategik dan Kinerja Karyawan terhadap Kinerja Perusahaan (Studi Kasus pada Perusahaan Persewaan Alat Pesta Oki Rejeki). Manajemen Dewantara, 1(2), 56-60.

Khan, M. A., Md Yusoff, R., Hussain, A., \& Binti Ismail, F. (2019). The mediating effect of job satisfaction on the relationship of HR practices and employee job performance: Empirical evidence from higher education sector. International Journal of Organizational Leadership, 8, 78-94.

Kurniasih, R. (2018). Pengaruh praktik manajemen sumber daya manusia berbasis Islam terhadap kepuasan kerja. Performance: Jurnal Personalia, Financial, Operasional, Marketing dan Sistem Informasi, 25(2), 23-27.

Küster, I., \& Canales, P. (2011). Compensation and control sales policies, and sales performance: the field sales manager's points of view. Journal of Business \& Industrial Marketing.

Lee, H., Boot, W. R., Basak, C., Voss, M. W., Prakash, R. S., Neider, M., . . . Gratton, G. (2012). Performance gains from directed training do not transfer to untrained tasks. Acta psychologica, 139(1), 146-158.

Lew, T. (2008). Perceived organizational support: linking human resource management practices with affective organizational commitment, professional commitment and turnover intention: Universiti Utara Malaysia Press.

Malik, M. E., Nawab, S., Naeem, B., \& Danish, R. Q. (2010). Job satisfaction and organizational commitment of university teachers in public sector of Pakistan. International journal of business and management, 5(6), 17.

Manning, M. L., Borton, D. L., \& Rumovitz, D. M. (2012). Infection preventionists' job descriptions: do they reflect expanded roles and responsibilities? American journal of infection control, 40(9), 888890.

Muiz, A., \& Muchsinati, E. S. (2017). Analisis Pengaruh Praktik Manajemen Sumber Daya Manusia Terhadap Kinerja Karyawan. Journal of Accounting and Management Innovation, 1(1), 49-63.

Nas, Z. (2016). The Effects Of Personal Determinants On Job Satisfaction Of Public And Private Universities'academicians In Pakistan. City University Research Journal, 6(2), 217-228.

Nwuche, C. A., \& Awa, H. O. (2011). Career planning and development: the realities in Nigerian organizations. International Business and Management, 2(2), 117127.

Osman, I., Ho, T. C., \& Galang, M. C. (2011). The relationship between human resource practices and firm performance: an empirical assessment of firms in Malaysia. Business Strategy Series.

Pfeffer, J. (1994). Competitive advantage through people: Unleashing the power of the work force.

Quresh, T. M., Akbar, A., Khan, M. A., Sheikh, R. A., \& Hijazi, S. T. (2010). Do human resource management practices have an impact on financial performance of banks? African Journal of Business Management, 4(7), 1281-1288.

Rehman, S. (2012). A study of public sector organizations with respect to recruitment, job satisfaction and retention. Global Business \& Management Research, 4(1).

Rogers, M. E., Creed, P. A., \& Glendon, A. I. (2008). The role of personality in adolescent career planning and exploration: A social cognitive perspective. Journal of Vocational Behavior, 73(1), 132-142.

Shiah-Hou, S. R., \& Cheng, C. W. (2012). Outside director experience, compensation, and performance. Managerial Finance.

Smeenk, S. G., Eisinga, R. N., Teelken, J., \& Doorewaard, J. (2006). The effects of HRM practices and antecedents on organizational commitment among university employees. The international 
journal of human resource management, 17(12), 2035-2054.

Tarique, I., Briscoe, D. R., \& Schuler, R. S. (2015). International human resource management: Policies and practices for multinational enterprises: Routledge.

Valeau, P. J., \& Paillé, P. (2019). The management of professional employees: linking progressive HRM practices, cognitive orientations and organizational citizenship behavior. The international journal of human resource management, 30(19), 2705-2731.

Vinzi, V. E., Trinchera, L., \& Amato, S. (2010). PLS path modeling: from foundations to recent developments and open issues for model assessment and improvement. In Handbook of partial least squares (pp. 47-82): Springer.

Wickramasinghe, V., \& Gamage, A. (2011). High-involvement work practices, quality results, and the role of HR function. The TQM Journal.

Wright, P. M., Gardner, T. M., \& Moynihan, L. M. (2003). The impact of HR practices on the performance of business units. Human resource management journal, 13(3), 2136.

Zerella, S., Von Treuer, K., \& Albrecht, S. L. (2017). The influence of office layout features on employee perception of organizational culture. Journal of Environmental Psychology, 54, 1-10. 